\title{
After-hours Power Status of Office Equipment in the USA
}

\author{
Carrie A. Webber*, Judy A. Roberson, Marla C. McWhinney, \\ Richard E. Brown, Margaret J. Pinckard, John F. Busch
}

Energy Analysis Department, Environmental Energy Technologies Division, Lawrence Berkeley National Laboratory, MS 90-4000,1 Cyclotron Road, Berkeley CA 94720, USA

Received 13 April 2005

\begin{abstract}
Office equipment is expected to be the fastest-growing segment of commercial energy use over the next 20 years, yet many aspects of office equipment energy use are poorly understood. User behavior, such as turning off devices at night or enabling power management, influences energy use to a great extent. The computing environment also plays a role both in influencing user behavior and in the success of power management. Information about turn-off rates and power management rates for office equipment was collected through a series of after-hours audits in commercial buildings. Sixteen businesses were recruited, including offices (small, medium and large offices in a variety of industries), schools, and medical buildings in California, Georgia, and Pennsylvania. The types and power states of office equipment found in these buildings were recorded and analyzed. This article presents these data for computers, monitors, printers, copiers, fax machines, scanners and multi-function devices. These data can be used to improve estimates of both energy consumption for these devices and savings from energy conservation efforts.
\end{abstract}

*Corresponding author. Fax: 1-510-486-4247.

Email address: cawebber@lbl.gov (C.A. Webber). 
Keywords: Office equipment; computers; power management; Energy Star; plug loads; commercial buildings

\section{Introduction}

The U.S. Department of Energy (DOE) projects that office equipment will be the fastestgrowing commercial end use between 2003 and 2025 [1]. Energy use for personal computers in the commercial sector is expected to grow an average 4.5 percent per year during this period, and energy use for other office equipment is expected to grow 4.8 percent per year. This is on top of the steep growth that occurred in the previous decade. Norford et al. [2] estimated 1988 office equipment energy consumption (including personal computers ( $\left.\mathrm{PCs}^{1}\right)$, monitors, and input/output devices $^{2}$ ) at $25 \mathrm{TWh}$. Office equipment energy consumption has since grown to about $75 \mathrm{TWh}^{3}$ $[3,4]$ in the United States.

Despite this rapid growth in energy use, office equipment has been the subject of relatively little scholarly research. Roth et al. [4] quantified annual electricity consumption of more than 30 office and telecommunications products for the Department of Energy. Webber et al. [5] described ongoing work in calculating savings attributable to the Environmental Protection Agency's (EPA) ENERGY STAR Program, which covers several major categories of office equipment. Kawamoto et al. [3] estimated office and network equipment energy use in the United States. Mungwititkul and

\footnotetext{
${ }^{1}$ The term "PC" is used throughout the paper to refer to all personal computers, regardless of manufacturer or operating system.

${ }^{2}$ This includes computer peripherals such as printers and scanners but not office equipment such as copiers and fax machines.
} 
Mohanty [6] estimated the energy-savings potential for office equipment in Thailand. The Energy Information Administration analyzes office equipment in some detail for its Annual Energy Outlook [1], the US government's official energy forecast. These analyses are bottom-up estimates; that is, they begin with estimates of such inputs as device power and usage, unit shipments, and device lifetimes and work "upward" to aggregate energy use and savings. Precise estimates of the underlying inputs are essential to accurately analyze this critical growth area.

Two key areas of uncertainty in estimating energy use are user behavior and power management (PM) rates. User behavior determines the number of hours per day during which a device is in use, the number of hours the device is turned on but idle, and the number of hours the device is off. PM can reduce the amount of power used by a device when it is turned on but not in active use.

Power management refers to a set of strategies used to reduce energy consumption of devices when they are not in active use, including such strategies as slowing a computer's clock rate, turning off power to certain circuits, and turning off the hard drive. These reduced power states are often referred to as low-power modes.

There is an extensive body of literature on PM and turn-off rates in office equipment. Nordman et al. [7] summarizes the results of 17 studies from 11 countries. These studies, done between 1990 and 1999, used a variety of methods including day or night audits (direct inspection of equipment status), user surveys, and continuous power or status monitoring to assess user

\footnotetext{
${ }^{3}$ Includes network equipment.
} 
behavior. More recently, Kawamoto et al. [8] used survey and audit data to characterize office equipment use in Japan, and Webber et al. [9] performed night audits in 11 buildings in the San Francisco Bay Area (CA) and Washington, DC. Buildings in California are disproportionately represented in past studies, as are government buildings.

Taken together, these studies do not present a cohesive picture of office equipment user behavior. PC turn-off rates range from zero percent [10] to 91 percent [7] (both one building studies), with the two most recent surveys reporting rates of 44 percent [9] (eleven buildings) and 82 percent [8] (four buildings). Results for other types of equipment also span wide ranges. This may reflect the small sample size of many of the studies, both in the numbers of devices included and the number of buildings. User behavior may also vary from region to region (e.g. Japanese results may differ from American results because Japanese and Americans have different usage patterns). User behavior may also be changing over time with the evolution of office equipment technology, software and computer networks.

The Energy Analysis Department at Lawrence Berkeley National Lab (LBNL) undertook this study to improve understanding of turn-off behavior and PM rates to better estimate overall energy use and gauge the effectiveness of power management technologies. It includes more buildings and more pieces of equipment than previous studies, and includes non-office and non-government buildings in several U.S. regions. The study consisted of a series of after-hours audits of office equipment in commercial buildings done as part of ongoing technical support of EPA's ENERGY $\mathrm{STAR}^{\circledR}$ program. Sixteen businesses were audited, including offices (small, medium and large offices in a variety of industries), schools, and medical buildings in the San Francisco Bay area (CA), Pittsburgh, PA, and Atlanta, GA. This article presents the results of these audits, including 
the numbers and types of office equipment found, their observed power states and PM delay settings (if applicable). ${ }^{4}$

\section{Power States and User Behavior}

For the purpose of this study, power states of office equipment are characterized as on, low power, or off. These are a simplified representation of a device's energy consumption profile: "On" and "low power" actually comprise a range of functionality and power use, depending on the product type. For example, for a laser printer, "on" includes not only the time spent creating an image, but also the time spent fully warmed up and ready to create an image with no delay, while "low power" may include intermittent power spikes to maintain certain device functions.

Table 1 [8] shows average power levels corresponding to on, low power and off. Actual power levels may vary widely between devices of the same type, depending on specific product characteristics. Low power modes represent a significant savings over on power, from 55 to 94 percent (for desktop computers and CRT monitors, respectively). Many devices, including almost all new computers and monitors, use some power even when turned off.

The relationship between user behavior and on and off modes is straightforward. Overwhelmingly, devices are on because someone turned them on manually or off because someone turned them off. There are some exceptions: some copiers have auto-off modes that function similarly to low power modes (see below), but are electrically identical to manual off. Computers, particularly laptops, may be set to "hibernate" either manually or automatically.

\footnotetext{
${ }^{4}$ These results were previously documented in Roberson et al. [11]. That report includes additional information about miscellaneous plug-load equipment found in the audits.
} 
Hibernate differs from off in that the contents of active memory are written to disk prior to shutting down. When restarted, the computer retrieves that information and resumes activity exactly as it was before shutting down. Power use does not differ between hibernate and off. Devices may also be turned off using power strips, which is electrically equivalent to unplugging the device.

The relationship between user behavior and power management is more complex. Users control whether PM features are enabled or disabled, and users can often choose the amount of idle time that must elapse before a device will enter a low power mode. User behavior determines when and for how long a device sits idle, and may be influenced by the computing environment. For example, users may be required to leave their computers on at night for network backups. Corporate culture also matters: users may turn off their computers simply because that is what others at their workplace do.

PM was originally developed for laptop computers to prolong battery life. In 1992, the EPA launched an energy conservation program called ENERGY STAR that initially sought to bring those same strategies to bear to address energy use of desktop computers and monitors, and later printers, copiers, fax machines, scanners, and multi-function devices. ${ }^{5}$ The ENERGY STAR program has proven quite successful and now most of these devices are capable of entering a low-power mode or "going to sleep" after a period of inactivity.

\footnotetext{
${ }^{5}$ The ENERGY STAR ${ }^{\circledR}$ program has expanded to include residential appliances and heating and cooling equipment, consumer electronics, building materials and components, refrigeration equipment, commercial buildings and new homes. Since 1996 it has been jointly administered by the U.S. EPA and DOE (http://energystar.gov/).
} 
Unfortunately, many devices capable of power management nonetheless do not successfully enter low power modes. Computer PM is subject to the complex combined effects of operating systems, application software, hardware and networks. Certain operating systems (e.g., Windows NT) effectively prevent PM from functioning. Background network activity may keep computers awake. If computers do succeed in entering low power mode, they may fail to respond to important network activity, which may lead to PM being disabled. Information about office equipment power status during non-business hours allows us to assess not just whether devices have PM enabled, but what share of devices are power managing successfully.

\section{Methodology}

For the purposes of this study, office equipment includes the following equipment categories and types:

- computers: desktop, laptop (notebook or mobile), server, and integrated computer system (ICS);

- monitors: cathode ray tube (CRT), and liquid crystal display (LCD);

- printers: impact, inkjet, laser, thermal, solid ink, blueprint, and wide format;

- fax machines: inkjet, laser, and thermal;

- copiers;

- scanners: document, flatbed, slide, and wide format; and

- multi-function devices: inkjet and laser.

\section{Building Sample}

According to the US Department of Energy's Commercial Buildings Energy Consumption Survey (CBECS) [12], 75 percent of all commercial computers were located in office, education 
and health care buildings in 1999. These buildings also have the highest computer density per square foot of the building activities tracked by CBECS. Offices and health care buildings also have high concentrations of photocopiers. Based on this information, site recruitment focused on schools, health care facilities, and offices.

The number of buildings and the number of regions included in the sample were determined by the project budget. The three regions were urban centers (representing a large pool of potential audit sites), chosen to represent the cultural and climatic variation in the United States.

Site recruitment is one of the most difficult and time-consuming aspects of commercial building surveys. Usually it involves cold-calling from a list of prospective business or building types (e.g., high schools), briefly describing the nature of the research activity, and trying to identify the person who is able and willing to grant after-hours access, which involves providing a key and/or escort. Most facilities have real concerns about safety, security, and privacy (e.g., of client or patient records), which of course must be addressed.

Each audit covered as much area as possible in four hours. At two sites a single floor was audited, at four sites the entire accessible space was audited, and at the remaining six sites audits included portions of two or three floors. In general, the greater the density and variety of equipment found, the less area was covered in four hours.

Table 2 outlines the buildings in the sample, which are identified by a letter. ${ }^{6}$ Floor areas are approximate gross square feet, based on floor plans or information from facility managers. The

\footnotetext{
${ }^{6}$ Site K, the "small office," is actually the aggregated results for five small businesses located in three different buildings: a graphics and printing business, an environmental consulting firm, a commodity brokerage firm, a
} 
appendix describes the buildings in more detail, but only in generic terms to preserve the anonymity of occupants. The initial target of the study was to collect data on at least 1,000 computers.

For the purposes of this study, a small office has fewer than 50 employees, a medium office has 50-500 employees, and a large office has more than 500 employees on site. The overall size of the company (which may have employees working in other locations) was not considered when characterizing the size of the office. Also, some audited offices occupied only a part of a larger building; the occupancy of the building as a whole was not a factor in characterizing office size. For example, site $\mathrm{E}$ is a branch office of a much larger company that occupies one floor of a highrise office tower. It was nonetheless categorized as a medium office based of the number of employees working for the audited firm at that location.

Table 2 also shows the approximate density of computers by gross square feet. For the six offices in the sample, the density of computers per employee is shown as well. Density per employee is not presented for other types of buildings: in some cases the number of employees was not available while for other buildings (e.g. high schools) it was deemed an inappropriate metric.

software development firm, and an engineering firm. The number of employees ranged from 4 to 25 , with a collective total of 77 employees. 


\section{Audit Protocol}

Each audit consisted of direct physical inspection of plug-load equipment in the audited building. Data collection was as unobtrusive as possible; researchers did not turn computers on or off or access any programs, settings, or files. If a workspace was occupied or obviously in use, it was bypassed and revisited at a later time, if possible.

For each unit of office equipment, researchers recorded the make (brand) and model as it appeared on the front or top of the unit. Monitor diagonal screen sizes were recorded, to the nearest inch, except those of laptops (for CRT monitors this measurement is smaller than the nominal screen (or tube) size). For laser printers and MFDs the user interface was accessed to determine the power management delay setting, which can range from 15 minutes to "never."

Researchers also tried to record whether or not each printer, copier, and MFD was connected to a network via cable (to the extent that networks become wireless, network connection will become more difficult to determine).

The power state of each unit was recorded as on, low, off, or unplugged (equipment that appeared never to be used was not recorded). Researchers were unable to distinguish auto-off from manual off for devices with an auto-off mode. If a paired monitor and computer were both on, the screen content was recorded; the most common occurrences were a screensaver, application, login or other dialog box (e.g., "It is now safe to turn off your computer"). When a monitor is off and the computer to which it is connected is not, it can be difficult to tell whether the computer is on or in low power. For PCs that appeared to be in low-power mode, a clamp-on current meter was used to measure relative current in the computer power cord before and after 
initiating a computer wake function, such as touching the mouse or keyboard. The PC was determined to have been in low-power mode if the change exceeded a pre-determined threshold.

The power state of a laptop computer is usually difficult to determine, unless it is in use and obviously on. A closed laptop has few external indicators, and those that are present are often ambiguous and inconsistent (e.g., between brands or models). In terms of improving estimates of laptop unit energy consumption, the most relevant data are the amount of time each laptop spends plugged in, and how often its battery is charged. At a minimum, data recorded for each laptop included whether or not it was plugged in.

In this study the term 'computer workstation' refers to any combination of computer(s) and monitor(s) physically used by one person at a time. Workstation configurations vary widely; most common is one desktop computer connected to one monitor, but researchers observed significant numbers of other configurations, including multiple computers with one monitor, multiple (usually LCD) monitors with one computer, and laptops used with a docking station and monitor. In this series of audits, each computer workstation was identified by a unique number; i.e., all components of each workstation were identified by the same number. This was done for two reasons: first, to facilitate subsequent analysis of the relationship between computer and monitor power states; and second, to be able to characterize the variety of workstations found. These analyses are discussed in the results section.

\section{Limitations of This Methodology}

One advantage of conducting after-hours building walk-throughs to collect data on office equipment power status is that a good variety and number of buildings can be recruited and audited. On the other hand, the data collected represent a snapshot in time, and do not capture 
variations in user behavior over time, which would require automated long-term time series metering of equipment power state and power levels.

This is the most robust sample of buildings to date for collecting data on the after hours power status of office equipment. It includes data on 1,683 computers (including desktops, ICSs, laptops and servers) and about $448,000 \mathrm{ft}^{2}$ in 12 commercial buildings, including schools and health care facilities in California, Georgia, and Pennsylvania. However, this sample should not be considered to be representative of commercial buildings as a whole or in part (e.g., by type, size, age, or location), or that the results presented here are statistically significant. It is a simply a record of what was found that hopefully will be of use to policy makers, researchers, and building managers.

\section{Results and Discussion}

The sample includes data on the power state of 1,453 desktop computers, 1,598 monitors, 353 printers, 89 servers, 79 MFDs, 50 laptop computers, 47 fax machines, 45 ICSs, 34 scanners, and 33 copiers. Among printers, the discussion of results will focus on the 158 laser and 123 inkjet printers found.

Among all buildings, computer density ranged from 1.7 to 9.4 units per $1000 \mathrm{ft}^{2}$ gross floor area (see Table 2). The only two buildings with a computer density less than 2 per $1000 \mathrm{ft}^{2}$ were offices (one medium, one large) whose employees tend to rely on laptop computers. Most laptops were absent during the audits; one of these companies requires employees to take their laptops home or lock them up when not at work. Office equipment density ranged from 4.5 to 19.3 units per $1000 \mathrm{ft}^{2}$ gross floor area, with an average of 8.8. Among office buildings only, computer 
density ranged from 0.53 to 2.18 per employee and office equipment density ranged from 1.4 to 4.5 units per employee, with an average of 3.2 .

When analyzing the numbers of equipment in each power state, two values are of primary interest: turn-off rates and power management rates. 'Turn-off rate' is the percent of each equipment type that was found turned off, while 'PM rate' is the percent of those not off that were found in low power.

Table 3 shows the numbers of each type of office equipment, and their after-hours power state. Table 3 does not include laptop computers, units that were unplugged, or units whose power state were unknown. ${ }^{7}$ Because copiers and MFDs often have long (2-4 hour) PM delay settings that may not have elapsed at the time of the audit, PM rates in Table 3 for this equipment should be considered a minimum or lower bound. Figure 1 graphically shows the breakdown by power state of each major type of office equipment.

Turn-off rates for PCs and monitors were much lower than found in previous studies [7, 8], with the exception of CADDET [10], which found a zero percent turn-off rate for PCs in one building, and Webber et al. [9], which found a comparable 32 percent turn-off rate for monitors. The printer turn-off rate was lower than in past studies $[8,9,13]$. The difference from past studies may be due to the larger and more diverse sample of buildings. The higher proportion of private enterprises, which have a markedly different corporate culture from government and research organizations, also may be a factor.

\footnotetext{
${ }^{7}$ A total of 97 devices had power states that were unknown or not recorded, about 2.5 percent of observed devices.
} 


\section{Computers}

Computers are categorized as desktop, integrated computer systems, servers, or laptops. Among 1,453 desktop computers the turn-off rate was 36 percent; it ranged from 5 percent (at Site E, a medium office) to 67 percent (at Site B, a medium office). Only 6 percent of all desktop computers that were not off were in low power. This PM rate is similar to the 5 percent rate found in a previous study [9]. The remaining 94 percent of computers either did not have PM enabled or it was enabled but not functioning due to other factors (discussed above). Among the 45 ICSs in Table 3 the turn-off rate was 60 percent, and the PM rate was 61 percent. However, it is possible that of the 11 ICSs found in low power, only the display (but not the CPU) was in low power.

Among education buildings in the study, the majority of the desktop computers, monitors and ICSs were found in classrooms with large numbers of PCs, clearly dedicated to computer-based learning. Between the two high schools, 65 percent of desktop computers and ICSs were found in computer labs with at least 15 (and up to 77) computers each; between the two university classroom buildings, 68 percent of desktop computers and ICSs were found in computer labs with at least 15 (and up to 57) computers each. Because a single instructor likely controls the afterhours power status of all equipment in a room, and also because school buildings in general experience fewer occupied hours per day and per year than other buildings, computer labs present a potentially rich target for energy-efficiency efforts in schools.

\section{Laptop Computers}

Fifty laptop computers were observed during the audits; power states were recorded for 37 of them. Of those 37, all but two (or 95 percent) were plugged in, either through their power cord or a docking station. Nine of the 37 laptops were clearly on; i.e., their display showed a desktop, application, or login screen. 
Sixty percent of the 35 laptops that were plugged in were plugged into docking stations. Of 107 docking stations found, 20 percent contained laptops, while 80 percent (85) were empty. Those empty docking stations are evidence of at least 85 more laptops that were absent at the time of the audits. In addition, 35 power cords with in-line power supplies (plugged in but unattached to any device) were identified as belonging to absent laptops. Combined with 50 observed laptops and 85 empty docking stations found, they suggest that at least 170 laptop computers are in use among the sample of buildings. Table 4 shows the breakdown of laptops, empty docking stations, and disconnected laptop power cords for each site. Additional laptops may have been taken home or locked away with no telltales left behind.

Table 4 also calculates the laptop share of all personal computers (laptops, desktops and integrated computer systems) at each site. Based on the above inferences, laptops are estimated to comprise at least 10 percent of non-server computers in the audited buildings. Some offices appear to have largely switched from desktop to laptop computers. In two offices in the study - one large and one medium office - the sum of laptop computers, empty docking stations and disconnected laptop power cords outnumbered the desktop computers found.

\section{Monitors}

The average turn-off rate among 1,329 CRT monitors was 32 percent; it ranged from 17 percent at Site E (medium office) and N (university) to 62 percent at Site D (high school). Somewhat surprisingly, the turn-off rate for LCD monitors was significantly lower at 18 percent. Power management rates for the two types of monitors were similar, 71 percent for CRTs and 75 percent for LCDs.

Table 5 shows the relationship between computer power state and monitor power state 
(monitors connected to more than one computer are not included in this table). Power management settings in the computer operating system control panels determine if and when the computer sends a signal to the monitor that causes the monitor to enter low power. If an ENERGY STAR-compliant monitor is attached to a computer that is on, it will enter low power only if it receives this signal. The "PC-initiated monitor PM rate" in Table 5 refers to the share of systems in which the computer signals the monitor to initiate PM, and the monitor responds. This rate can be inferred only among systems in which the computer is on and the monitor is not turned off.

An ENERGY STAR-compliant monitor can also enter low power if there is no video signal from the computer, either because the computer is off, it is in low power, or the monitor is disconnected from the computer. The "Monitor PM rate" in Table 5 refers to the share of monitors that power manage in the absence of a video signal from the computer.

Monitors connected to computers that were off or absent had monitor power management rates close to 100 percent. The few monitors that failed to enter a low power mode may have been incapable of power managing (i.e., non-ENERGY STAR-compliant). PC-initiated power management rates were markedly lower. Clearly, monitors that depended on a computer signal to initiate power management were much less likely to enter low power.

Webber et al. [9] speculate that monitors in low power might be thought by users to be off. Among buildings in this report, Site $\mathrm{M}$, a large office, offers anecdotal evidence regarding user (mis)interpretation of monitor power state. According to the facility manager, this company's strict policy is that employees turn their monitors off before leaving, and security personnel turn off any monitors found left on. The audit found that only 4 percent of monitors at the site were on, but only 29 percent were actually off; the remaining 65 percent were in low power mode. This 
supports anecdotal evidence that if a display is black or blank, users often assume the monitor is off, even though the front panel power indicator (which is amber and/or blinking when the unit is in low power) indicates otherwise.

Seventeen percent of all monitors found were LCDs. Table 6 shows the breakdown of LCD and CRT monitors by site. At three sites (including two high schools, D and F) no LCD monitors were found, but at two sites (E, medium office, and A, university building), LCD monitors outnumbered CRT monitors, and at three others (B and $\mathrm{H}$, both medium offices; and $\mathrm{J}$, health care) LCDs were over 25 percent of all monitors found.

While the building sample is not large enough to draw reliable conclusions about office equipment power management based on building type, the analysis shows some interesting variation. Figure 2 shows the after-hours power status of monitors (both CRT and LCD) based on building type. (A similar analysis for desktop computers and ICSs was not performed because almost all the computers found in low power were in a single (health care) building.)

In the sample, monitor PM rates were by far the lowest in high schools (44\%) and highest in university buildings (85\%) and large offices $(87 \%)$. Monitor turn-off rates were lowest in university buildings (13\%) and highest in small offices (50\%). In addition to the low monitor PM rate, a relatively high number $(35 \%)$ of monitors were on in high schools, where all monitors found were CRTs, which use significantly more power when on than LCDs [8]. This strengthens the evidence that there is significant energy savings potential among office equipment in computer classrooms, and particularly those in high schools. 


\section{Printers}

Printers are categorized by imaging technology: laser, inkjet, impact, thermal, solid ink, and blueprint. Figure 3 shows the composition of the sample. Two percent of the printers found were wide format, meaning they can accommodate 17 "x 22 " or larger paper.

The presence or absence of a network connection was recorded for a subset of printers. Within this subset, 63 percent of laser printers but only 7 percent of inkjet printers were networked.

Low power delays (that is, the amount of time that must elapse with no activity before a printer will enter a low power mode) can often be changed through interactive menus. During the audits, delay settings were recorded for 78 laser printers. The results are shown in Figure 4. Ninety-five percent of these printers were set to power manage, markedly higher than the 60 percent power management rate actually observed during the audits (see Table 3). Not all laser printers can power manage (i.e., they are not ENERGY STAR-compliant), and so do not have power management delay settings. Among laser printers that can power manage, there are several reasons they might be found on during an audit: (1) the printer has a long (3-4 hour) power management delay setting, which had not elapsed, (2) the printer was recently used, or (3) the printer was in error mode, which prevented it from entering low power.

\section{Other Equipment}

Many units of office equipment that were identified in the field as copiers, fax machines, or printers turned out, on later examination of their specifications, to be multi-function devices. Turn-off and PM rates were similar for laser and inkjet MFDs (Table 3). 
The low PM rate for MFDs and copiers may be due in part to the fact that these devices often have power management delay settings of two hours or more. It is possible that some of the devices found on would eventually have entered low power.

It can be difficult to tell whether a fax machine is on or in low power. Also, many units meet ENERGY STAR's low power requirement when on but idle or 'ready', and so do not need a separate low power mode. In this study, unless a fax machine gave a visual indication that it was in low power, it was recorded as being on. Of the 44 fax machines whose technology was determined, $69 \%$ (30) were laser, $20 \%$ (9) were thermal, and $11 \%$ (5) were inkjet.

Of the total 37 scanners in the sample, $76 \%$ (28) were flatbed scanners, $14 \%$ (5) were specialized document scanners, 5\% (2) were wide format, and 5\% (2) were slide scanners. Among flatbed scanners only, $18 \%$ (5) were on, $43 \%$ (18) were in low power, $29 \%$ (8) were off, and $11 \%$ (3) were unplugged. All five document scanners were off; both wide format scanners were found in the same room, and were on.

\section{Implications for Energy Use}

To illustrate the consequences of user behavior on energy use, total energy use was calculated for the devices found in the audits under four usage scenarios: as found, all devices successfully power managing (taking turn-off rates as fixed), all devices turned off after hours (taking PM rates as fixed), and all devices both successfully power managing and turned off at night.

For the "as found" scenario, units found on in the audits are assumed to be on 100 percent of the time, never turned off and never entering low power mode. Units found in low power mode are assumed to never be turned off, but reliably enter low power mode after hours and for some portion of a typical workday. Units found off are assumed to represent a mix of power-managed 
and not power-managed (according to the PM rates found in the study), but are assumed to be regularly turned off after hours. The basic usage patterns for devices that are both turned off and power managed are shown in Table 7. Time distributions for other usage patterns were derived from this basic pattern (e.g., a printer with PM that is not turned off at night is on 22 percent of the time and in low power 78 percent of the time; a printer that is not power managed but is turned off at night is on 28 percent of the time and off 72 percent of the time).

Unit energy consumptions were calculated for selected product types using these usage patterns and the power levels given in Table 1 (MFD power consumption is assumed to be the same as copier power consumption). The total energy consumption for all units in the study was then calculated for each of the four scenarios. The results, shown in Table 8, suggest that energy use could be reduced by a factor of 2.6 through turn-off behavior alone, or by a factor of 2.9 through turn-off behavior and fully successful power management.

\section{Conclusions}

The data collected in this study provide a starting point for accurately estimating office equipment energy use and the savings, current and potential, from power management.

Turn-off rates vary widely over the types of office equipment, from 0 percent (for fax machines) to 75 percent (for wide-format printers). For most equipment types, turn-off rates are under 50 percent.

For the many devices left on at night, is energy consumption being reduced through power management? Here, again, results differ sharply by product. Only 6 percent of desktop computers in this study were found to successfully enter low power mode, and only 53 percent successfully 
initiated power management in monitors. Clearly there is significant room for improvement in power management of computers. In contrast, $96-98$ percent of monitors connected to computers that were not on were found in low power, so a very high proportion of monitors are ENERGY STAR compliant and capable of power managing themselves. Among laser printers, only five percent had power management disabled, but for reasons discussed above (including error modes and after-hours network use), the actual PM rate for laser printers was only 60 percent.

The results of this study reflect several trends in office equipment. The study found evidence of the growing use of laptop computers, especially as a replacement for a desktop computer. Because of their inherent portability, accounting for laptops is difficult, especially during an afterhours audit, but a conservative estimate is that laptops comprise at least 10 percent of the nonserver computers used in the audited buildings. Laptops outnumbered desktop computers at two sites: one medium and one large office. To the extent that relatively energy-efficient laptops are replacing desktop computers, significant electrical energy is saved. However, more work is needed to characterize laptop usage patterns, which are more complex than desktop usage patterns.

Market penetration of LCD monitors, which use significantly less energy when on than CRT monitors, is also increasing rapidly. They outnumbered CRT monitors at two of the twelve sites in the study: a medium office and a university classroom building. However, no LCD monitors were found at three sites (two high schools and a large office). The market share of LCD monitors can be expected to continue to grow as older CRT monitors are replaced and LCD monitor technology improves and becomes more affordable. Multifunction devices were much more prevalent in this audit than in Webber et al. [9]. However, while most MFDs can also fax, print, and scan, the study did not find a corresponding decrease in the relative number of fax machines, 
printers and scanners, perhaps suggesting that MFDs are used primarily as copiers, and are multifunction only in name.

While power management is currently making a small dent in energy use for some equipment types, a significant amount of energy continues to be wasted by office equipment that is not in active use. Improving the performance of power management (particularly for PCs connected to networks) and increasing usage of PM features have enormous energy-saving potential. Capturing those savings will require additional research and effort on the part of the both policy makers and the office equipment industry. 


\section{Acknowledgements}

The work described in this paper was supported by the Office of Atmospheric Programs, Climate Protection Partnerships Division of the U.S. Environmental Protection Agency and prepared for the U.S. Department of Energy under Contract No. DE-AC03-76SF00098.

This study would not have been possible without the support of the ENERGY STAR Office Equipment program, as well as the cooperation of the owners and facility managers of the businesses, institutions, and organizations that participated in the study. We would like to thank our reviewers Jim McMahon, Bruce Nordman, David Fridley and Steve Greenberg of LBNL; Kent Dunn and Michael Thelander of Verdiem: Energy Efficiency for PC Networks, Seattle WA; and Terry O'Sullivan of Energy Solutions, Oakland CA. Thanks also to the anonymous referees for their helpful comments. 


\section{Appendix: Building Descriptions}

\section{Site A}

University classroom building, Atlanta GA

Urban, downtown campus; 4-story, circa 1970

Area surveyed includes chemistry and computer laboratory/classrooms, faculty offices, lecture hall, lobby, and storage.

\section{Site B}

Medium office, Pittsburgh PA

Headquarters of a national non-profit organization

Suburban office park, 3-story, new in 2002

Area surveyed includes computer lab/shop, conference, cubicles, custodial, kitchen, lounge, network closet, offices, print/copy centers, reception, server room, and shipping \& receiving.

\section{Site C}

Large office, Atlanta GA

National headquarters of an internet company

Midtown office building, 8-story, circa 1970s

Area surveyed includes customer call center, computer classrooms, break room, conference, cubicles, offices, and print/copy centers.

\section{Site D}

Urban high school, CA 
3-story main building, new in 2001

Area surveyed includes administrative offices, audio/visual studio, bookroom, classrooms, computer classrooms, conference, library, teachers lounge, network closet, print/copy center, and utility/mechanical. Most computers are found in a few rooms, including computer classrooms and the library.

\section{Site E}

Medium office, Atlanta GA

Branch office of an international consulting firm

One floor of a 1990s suburban office tower

Area surveyed includes break room, conference, cubicles, lounge, offices, print/copy centers, and server room. This office had a high percentage of laptop computers, which must be locked up or taken home at night. Only administrative staff members have desktop computers, which are left on at night for backups and updates.

\section{Site F}

Urban high school, Pittsburgh PA

3-story main building, remodeled in 1990s

Area surveyed includes auditorium, cafeteria, classrooms (including art, band, language, computer classrooms, conference, library, teachers lounge, network closet, offices, storage, and A/V workroom. Most computers are found in a few classrooms and the library.

\section{Site G}

Outpatient clinic, San Francisco CA 
10-story urban medical campus building

Area surveyed includes conference, cubicles medical labs, library, lounges, exam rooms

(including E/N/T, general medicine, ophthalmology, pediatric), nurses'stations, offices, patient

registration, phone bank, medical utility, treatment rooms, and waiting. Each exam and treatment room had a computer/monitor.

\section{Site H}

Medium office, Atlanta GA

Information services department of a university

6-story urban campus building, circa 1970s

Area surveyed includes break room, conference, copy/print center, cubicles, custodial, lounge, network closet, offices, server room, and utility/mechanical.

\section{Site J}

Medical office building, Pittsburgh PA

Suites of physicians in private practice

5-story suburban building, Area surveyed includes break room, conference, exam rooms (including cardiology, E/N/T, endocrinology, ophthalmology, sleep disorders, urology), kitchen, labs, offices, server room, storage, utility, and waiting.

\section{Site K}

Small office, Pittsburgh PA

5 small businesses in 3 different suburban buildings 
Area surveyed includes break room, conference, copy/print center, cubicles, electronics shop, network closet, offices, server room, and storage.

\section{Site M}

Large office, Pittsburgh PA

Corporate headquarters of a major manufacturer

Urban downtown office building, 6-story, new in 2001

Area surveyed includes conference, copy/print centers, cubicles, kitchen, lounge, health center, and offices. Many employees in this office use laptop computers. Company policy is to turn monitors off at night (to prevent fires); special permission is required to bring in or use small appliances (fans, heaters, lamps, etc).

\section{Site N}

University classroom building, Atlanta GA

Urban, downtown campus; 4-story, circa 1960

The area surveyed included computer laboratories and classrooms, other classrooms, and offices of faculty, staff, and graduate students. 



\section{References}

[1] US Department of Energy. Annual energy outlook 2005 with projections to 2025. Washington, DC: Energy Information Administration, DOE/EIA-0383 (2005), 2005. See also: http://www.eia.doe.gov/oiaf/aeo/.

[2] Norford L, Rabl A, Harris J, Roturier J. Electronic office equipment: the impact of market trends and technology on end-use demand for electricity. In: Johansson T, Bodlund B, Williams R, Editors. Electricity: efficient end-use and new generation technologies, and their planning implications. Lund, Sweden: Lund University Press, 1989. p. 427-459.

[3] Kawamoto K, Koomey J, Nordman B, Brown R, Piette MA, Ting M, Meier A. Electricity used by office equipment and network equipment in the U.S. Energy 2002;27:255-269.

[4] Roth K, Goldstein F, Kleinman J. Energy consumption by office and telecommunication equipment in commercial buildings volume 1: energy consumption baseline. Washington, DC: US DOE Office of Building Technology State and Community Programs, Arthur D Little $\begin{array}{lllll}\text { Reference } & \text { No. } & 72895-00, & \text { See } & \text { also: }\end{array}$ http://www.eere.energy.gov/buildings/info/documents/pdfs/office_telecom-vol1_final.pdf.

[5] Webber CA, Brown RE, Koomey JG. Savings estimates for the Energy Star ${ }^{\circledR}$ voluntary labeling program. Energy Policy 2000;28:1137-1149.

[6] Mungwititkul W, Mohanty, B. Energy efficiency of office equipment in commercial buildings: the case of Thailand. Energy 1997;22:673-680. 
[7] Nordman B, Meier A, Piette MA. PC and monitor night status: Power management enabling and manual turn-off. In: Proceedings of the 2000 ACEEE summer study on energy efficiency in buildings, vol. 7. Washington, DC: American Council for an Energy-Efficient Economy, 2000. p. 89-99. See also: http://www.aceee.org/pubsmeetings/index.htm.

[8] Kawamoto K, Shimoda Y, Mizuno M. Energy saving potential of office equipment power management. Energy and Buildings 2004;36:915-923.

[9] Webber CA, Roberson JA, Brown RE, Payne CT, Nordman B, Koomey JG. Field surveys of office equipment operating patterns, report number LBNL-46930. Berkeley, CA: Lawrence Berkeley National Laboratory, 2001. See also: http://www-library.lbl.gov/lbnl_reports/sf.

[10] CADDET Energy Efficiency. PowerSaver energy-saving device for idle computer monitors, report number R357. Sittard, the Netherlands: CADDET Energy Efficiency, 1999. See also: http://www.caddet.org/brochures/index.php.

[11] Roberson JA, Webber CA, McWhinney MC, Brown RE, Pinckard MJ, Busch JF. After-hours power status of office equipment and energy use of miscellaneous plug-load equipment, report number LBNL-53729-revised. Berkeley, CA: Lawrence Berkeley National Laboratory, 2004. See also: http://www-library.lbl.gov/lbnl_reports/sf.

[12] US Department of Energy. Computers and photocopiers in commercial buildings (1999 CBECS Data). Washington, DC: Energy Information Administration. 2002. See also: http://www.eia.doe.gov/emeu/cbecs/pc_copier/pccopier99.html

[13] Bryntse G, Enoksson E. Energy efficient office equipment, report number P 1440 GT. Falun, Sweden: Dalarna University College, 1998. Högskolan Dalarna, 79188 Falun, Sweden. 

Table 1. Representative power levels for selected office equipment

\begin{tabular}{|c|c|c|c|c|}
\hline & & On $(\mathrm{W})$ & Low power (W) & Off (W) \\
\hline \multirow[t]{2}{*}{$\mathrm{PC}$} & Desktop & 55 & 25 & 1.5 \\
\hline & Laptop & 15 & 3 & 2 \\
\hline \multirow[t]{2}{*}{ Monitor } & CRT & 85 & 5 & 0.5 \\
\hline & LCD & 15 & 1.5 & 0.5 \\
\hline \multicolumn{2}{|c|}{ Copier (monochrome) } & 185 & 76 & 8.7 \\
\hline \multicolumn{2}{|c|}{ Laser printer } & 77 & 25 & 1 \\
\hline
\end{tabular}


Table 2. Building sample and computer density

\begin{tabular}{|c|c|c|c|c|c|c|c|c|}
\hline \multirow{2}{*}{ site } & \multirow{2}{*}{ state } & \multirow{2}{*}{ building type } & \multirow{2}{*}{ occupancy } & \multicolumn{3}{|c|}{ approximate no. in area surveyed } & \multicolumn{2}{|c|}{ computer density per } \\
\hline & & & & computers & $\mathrm{ft}^{2}$ & employees & $1000 \mathrm{ft}^{2}$ & employee \\
\hline $\mathbf{A}$ & GA & education & university classroom bldg & 171 & 28,000 & $\mathrm{n} / \mathrm{a}$ & 6.1 & $\mathrm{n} / \mathrm{a}$ \\
\hline B & PA & medium office & non-profit headquarters & 182 & 55,000 & 128 & 3.3 & 1.42 \\
\hline $\mathbf{C}$ & GA & large office & corporate headquarters & 262 & 28,000 & 120 & 9.4 & 2.18 \\
\hline D & $\mathrm{CA}$ & education & high school & 112 & 40,000 & $\mathrm{n} / \mathrm{a}$ & 2.8 & $\mathrm{n} / \mathrm{a}$ \\
\hline $\mathbf{E}$ & GA & medium office & business consulting firm & 37 & 22,000 & 70 & 1.7 & 0.53 \\
\hline $\mathbf{F}$ & PA & education & high school & 248 & 100,000 & $\mathrm{n} / \mathrm{a}$ & 2.5 & $\mathrm{n} / \mathrm{a}$ \\
\hline $\mathbf{G}$ & $\mathrm{CA}$ & health care & outpatient clinic & 177 & 45,000 & $\mathrm{n} / \mathrm{a}$ & 3.9 & $\mathrm{n} / \mathrm{a}$ \\
\hline $\mathbf{H}$ & GA & medium office & information services dept & 153 & 24,000 & 76 & 6.4 & 2.01 \\
\hline $\mathbf{J}$ & PA & health care & private physicians' offices & 56 & 26,000 & $\mathrm{n} / \mathrm{a}$ & 2.2 & $\mathrm{n} / \mathrm{a}$ \\
\hline $\mathbf{K}$ & PA & small office & 5 small businesses combined & 117 & 20,000 & 77 & 5.9 & 1.52 \\
\hline $\mathbf{M}$ & PA & large office & corporate headquarters & 73 & 40,000 & 125 & 1.8 & 0.58 \\
\hline \multirow[t]{2}{*}{$\mathbf{N}$} & GA & education & university classroom bldg & 95 & 20,000 & $\mathrm{n} / \mathrm{a}$ & 4.8 & $\mathrm{n} / \mathrm{a}$ \\
\hline & & & total & 1,683 & 448,000 & \multicolumn{3}{|c|}{$\mathrm{n} / \mathrm{a}=$ not available } \\
\hline
\end{tabular}


Table 3. Office equipment: After-hours power states

\begin{tabular}{|c|c|c|c|c|c|c|c|c|c|}
\hline \multicolumn{2}{|c|}{ Equipment } & \multicolumn{4}{|c|}{ Number } & \multicolumn{4}{|c|}{ Percent } \\
\hline Category & Type & on & low & off & sum & on & low & off & PM rate \\
\hline \multirow[t]{3}{*}{ computers } & desktop & 869 & 60 & 524 & 1453 & $60 \%$ & $4 \%$ & $36 \%$ & $6 \%$ \\
\hline & server & 87 & & 2 & 89 & $98 \%$ & $0 \%$ & $2 \%$ & $\mathrm{n} / \mathrm{a}$ \\
\hline & ICS & 7 & 11 & 27 & 45 & $16 \%$ & $24 \%$ & $60 \%$ & $61 \%$ \\
\hline \multirow[t]{2}{*}{ monitors } & CRT & 259 & 648 & 422 & 1329 & $19 \%$ & $49 \%$ & $32 \%$ & $71 \%$ \\
\hline & LCD & 56 & 164 & 49 & 269 & $21 \%$ & $61 \%$ & $18 \%$ & $75 \%$ \\
\hline \multirow[t]{6}{*}{ printers } & laser & 53 & 81 & 24 & 158 & $34 \%$ & $51 \%$ & $15 \%$ & $60 \%$ \\
\hline & inkjet & 86 & & 37 & 123 & $70 \%$ & $\mathrm{n} / \mathrm{a}$ & $30 \%$ & $\mathrm{n} / \mathrm{a}$ \\
\hline & impact & 16 & & 6 & 22 & $73 \%$ & $\mathrm{n} / \mathrm{a}$ & $27 \%$ & $\mathrm{n} / \mathrm{a}$ \\
\hline & thermal & 31 & & 7 & 38 & $82 \%$ & $\mathrm{n} / \mathrm{a}$ & $18 \%$ & $\mathrm{n} / \mathrm{a}$ \\
\hline & wide format ${ }^{\mathrm{b}}$ & 2 & & 6 & 8 & $25 \%$ & $0 \%$ & $75 \%$ & $0 \%$ \\
\hline & solid ink & 1 & 3 & & 4 & $25 \%$ & $75 \%$ & $0 \%$ & $75 \%$ \\
\hline \multirow[t]{2}{*}{ MFDs } & inkjet & 9 & 4 & 3 & 16 & $56 \%$ & $25 \%$ & $19 \%$ & $31 \%$ \\
\hline & laser & 36 & 14 & 13 & 63 & $57 \%$ & $22 \%$ & $21 \%$ & $28 \%$ \\
\hline copiers & all & 12 & 5 & 16 & 33 & $36 \%$ & $15 \%$ & $48 \%$ & $29 \%$ \\
\hline fax machines & all & 44 & 3 & & 47 & $94 \%$ & $6 \%$ & $0 \%$ & $6 \%$ \\
\hline scanners & all & 8 & 12 & 14 & 34 & $24 \%$ & $35 \%$ & $41 \%$ & $60 \%$ \\
\hline
\end{tabular}

a"PM rate" is the percent of units not off that were in low power.

${ }^{b}$ Of the 8 wide format printers found, six were inkjets (four off, two on), one was a blueprint printer (off) and one was thermal (off). A wide format impact printer was also observed but its power state was not recorded. These devices are not included in the reported results for inkjet and thermal printers. 
Table 4. Observed and inferred laptop computers by site

Sorted by laptop share of total personal computers

\begin{tabular}{|c|c|c|c|c|c|c|}
\hline \multirow[b]{2}{*}{ Site } & \multirow[b]{2}{*}{$\begin{array}{c}\text { no. of desktop } \\
\text { computers and } \\
\text { ICSs } \\
\end{array}$} & \multicolumn{4}{|c|}{ Number of laptop computers } & \multirow{2}{*}{$\begin{array}{c}\text { Laptops as a } \\
\% \text { of all } \\
\text { personal } \\
\text { computers }\end{array}$} \\
\hline & & $\begin{array}{l}\text { observed } \\
\text { laptops }\end{array}$ & $\begin{array}{l}\text { empty docking } \\
\text { stations }\end{array}$ & $\begin{array}{l}\text { empty laptop } \\
\text { power cords }\end{array}$ & $\begin{array}{l}\text { estimated total } \\
\text { laptops }\end{array}$ & \\
\hline $\mathbf{M}$ & 41 & 26 & 42 & 9 & 77 & $65 \%$ \\
\hline $\mathbf{E}$ & & 4 & 12 & 13 & 29 & \\
\hline $\mathbf{H}$ & & 3 & 15 & 7 & 25 & \\
\hline $\mathbf{P}$ & & 7 & 0 & 2 & 9 & \\
\hline $\mathbf{J}$ & & 4 & 0 & 0 & 4 & \\
\hline $\mathbf{C}$ & & 0 & 14 & 4 & 18 & \\
\hline $\mathbf{K}$ & & 3 & 0 & 0 & 3 & \\
\hline D & & 1 & 1 & 0 & 2 & \\
\hline $\mathbf{A}$ & & 1 & 1 & 0 & 2 & \\
\hline B & & 1 & 0 & 0 & 1 & \\
\hline $\mathbf{F}$ & & 0 & 0 & 0 & 0 & \\
\hline $\mathbf{G}$ & & 0 & 0 & 0 & 0 & \\
\hline Total & & 50 & 85 & 35 & 170 & \\
\hline
\end{tabular}


Table 5. Analysis of monitor power management by computer power state

\begin{tabular}{|c|c|c|c|c|c|c|c|}
\hline \multirow[b]{2}{*}{ Computer } & \multirow[b]{2}{*}{ Computer Power state } & \multirow[b]{2}{*}{ No. } & \multicolumn{3}{|c|}{ Monitor Power State } & \multicolumn{2}{|c|}{ Monitor Power Management ${ }^{\text {a }}$} \\
\hline & & & Off & Low & On & $\begin{array}{l}\text { Monitor PM Rate } \\
\text { (computer is off } \\
\text { or in low power) }\end{array}$ & $\begin{array}{c}\text { PC-initiated } \\
\text { Monitor PM Rate } \\
\text { (computer is on) }\end{array}$ \\
\hline \multirow[t]{3}{*}{ Desktop } & Off/no video signal & 433 & 184 & 244 & 5 & $98 \%$ & \\
\hline & Low & 59 & 4 & 53 & 2 & $96 \%$ & \\
\hline & On & 689 & 154 & 286 & 249 & & $53 \%$ \\
\hline \multirow[t]{2}{*}{ Laptop $^{b}$} & Absent or empty docking station & 55 & 13 & 42 & 0 & $100 \%$ & \\
\hline & Plugged-in or in docking station & 23 & 4 & 15 & 4 & $79 \%$ & \\
\hline Server & On & 32 & 14 & 10 & 8 & & $56 \%$ \\
\hline
\end{tabular}

${ }^{\mathrm{a}}$ Monitor power management rate is the percent of monitors not off that are in low power.

${ }^{b}$ These data refer to external monitors connected to laptop computers, not to the laptop display. 
Table 6. Number and percent of LCD monitors, by site sorted by percent of LCD monitors

\begin{tabular}{cccccccccccccc}
\hline site & $\mathbf{D}$ & $\mathbf{F}$ & $\mathbf{C}$ & $\mathbf{M}$ & $\mathbf{G}$ & $\mathbf{K}$ & $\mathbf{N}$ & $\mathbf{J}$ & $\mathbf{H}$ & $\mathbf{B}$ & $\mathbf{A}$ & $\mathbf{E}$ & all \\
\hline LCDs & 0 & 0 & 2 & 4 & 12 & 14 & 13 & 18 & 40 & 66 & 96 & 21 & 286 \\
CRTs & 89 & 248 & 254 & 97 & 162 & 88 & 76 & 46 & 104 & 111 & 79 & 12 & 1366 \\
\hline total & 89 & 248 & 256 & 101 & 174 & 102 & 89 & 64 & 144 & 177 & 175 & 33 & 1652 \\
$\%$ LCDs & $0 \%$ & $0 \%$ & $0 \%$ & $4 \%$ & $7 \%$ & $14 \%$ & $15 \%$ & $28 \%$ & $28 \%$ & $37 \%$ & $55 \%$ & $64 \%$ & $17 \%$ \\
\hline
\end{tabular}


Table 7. Basic usage pattern for devices both turned off after hours and power managed, percent time in mode ${ }^{\mathrm{a}}$

\begin{tabular}{lccc} 
& On & Low & Off \\
\hline PCs & $13 \%$ & $5 \%$ & $81 \%$ \\
Monitors (CRT and LCD) & $13 \%$ & $5 \%$ & $81 \%$ \\
Copiers and MFDs & $34 \%$ & $0 \%$ & $66 \%$ \\
Printers & $22 \%$ & $6 \%$ & $72 \%$ \\
\hline
\end{tabular}

${ }^{a}$ Usage patterns are derived from Kawamoto et al. [8]. Average PM delay times are assumed to be 15 minutes for computers and monitors, 60 minutes for copiers, and 30 minutes for printers. MFDs are assumed to have the same usage pattern as copiers. The number of "business days" per year (usage patterns in [8] are for a typical business day) is assumed to be 235 for PCs and monitors (52 weeks less 10 holidays and 15 vacation/sick/travel days) and 250 for copiers and printers (no vacation/sick/travel days were assumed because these devices typically have multiple users). 
Table 8. Estimated energy use for selected equipment: Four behavior scenarios

\begin{tabular}{|c|c|c|c|c|c|c|c|c|}
\hline & Uni & $\begin{array}{r}\text { Energy } \\
\text { (kWh }\end{array}$ & $\begin{array}{l}\text { nnsumptic } \\
\text { yr) }\end{array}$ & & Tot & $\begin{array}{r}\text { Energy Use } \\
\text { (M }\end{array}$ & $\begin{array}{l}\text { or Device } \\
\text { Wh/yr) }\end{array}$ & in Sample \\
\hline & $\begin{array}{l}\text { No PM, } \\
\text { always on }\end{array}$ & $\begin{array}{c}\text { PM, } \\
\text { always } \\
\text { on }\end{array}$ & $\begin{array}{c}\text { No PM, } \\
\text { turned } \\
\text { off } \\
\end{array}$ & $\begin{array}{l}\text { PM, } \\
\text { turned } \\
\text { off } \\
\end{array}$ & $\begin{array}{c}\text { As } \\
\text { Found }\end{array}$ & $\begin{array}{c}100 \% \\
\text { successful } \\
\text { PM } \\
\end{array}$ & $\begin{array}{c}\text { All } \\
\text { Turned } \\
\text { Off }\end{array}$ & $\begin{array}{c}\text { All Turned } \\
\text { Off \&100\% } \\
\text { successful PM }\end{array}$ \\
\hline Desktop PC & 482 & 254 & 100 & 86 & 486 & 280 & 144 & 125 \\
\hline CRT Monitor & 745 & 136 & 141 & 104 & 329 & 167 & 152 & 138 \\
\hline LCD Monitor & 131 & 29 & 28 & 22 & 13 & 7.4 & 6.2 & 5.8 \\
\hline MFD, laser & 1621 & 993 & 605 & 605 & 80 & 58 & 38 & 38 \\
\hline Copiers & 1621 & 993 & 605 & 605 & 34 & 27 & 20 & 20 \\
\hline Printers, laser & 675 & 320 & 197 & 170 & 66 & 47 & 28 & 27 \\
\hline Total & & & & & 1,009 & 586 & 389 & 353 \\
\hline
\end{tabular}




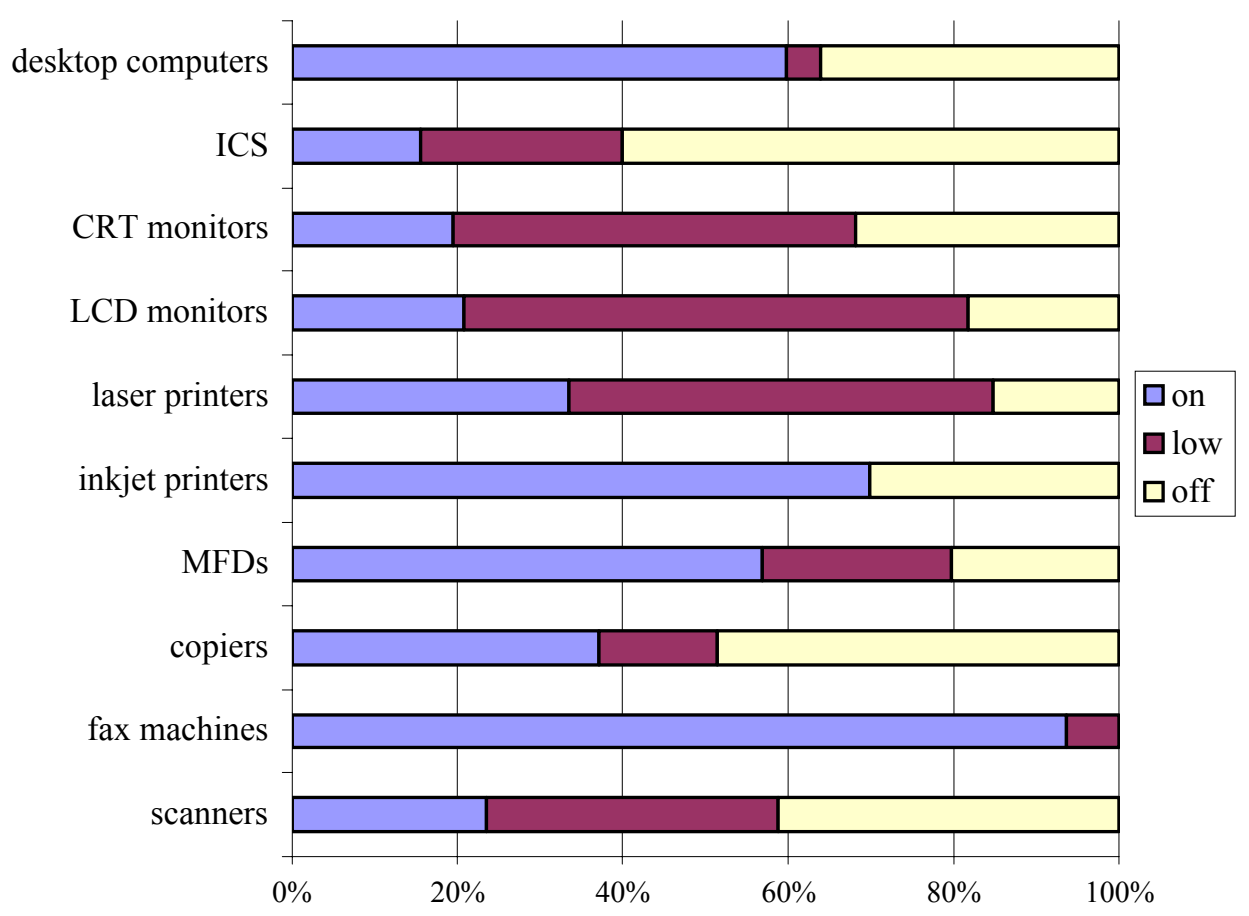

Figure 1 Office equipment power states 
Figure 2. Monitor after-hours power status, by building type

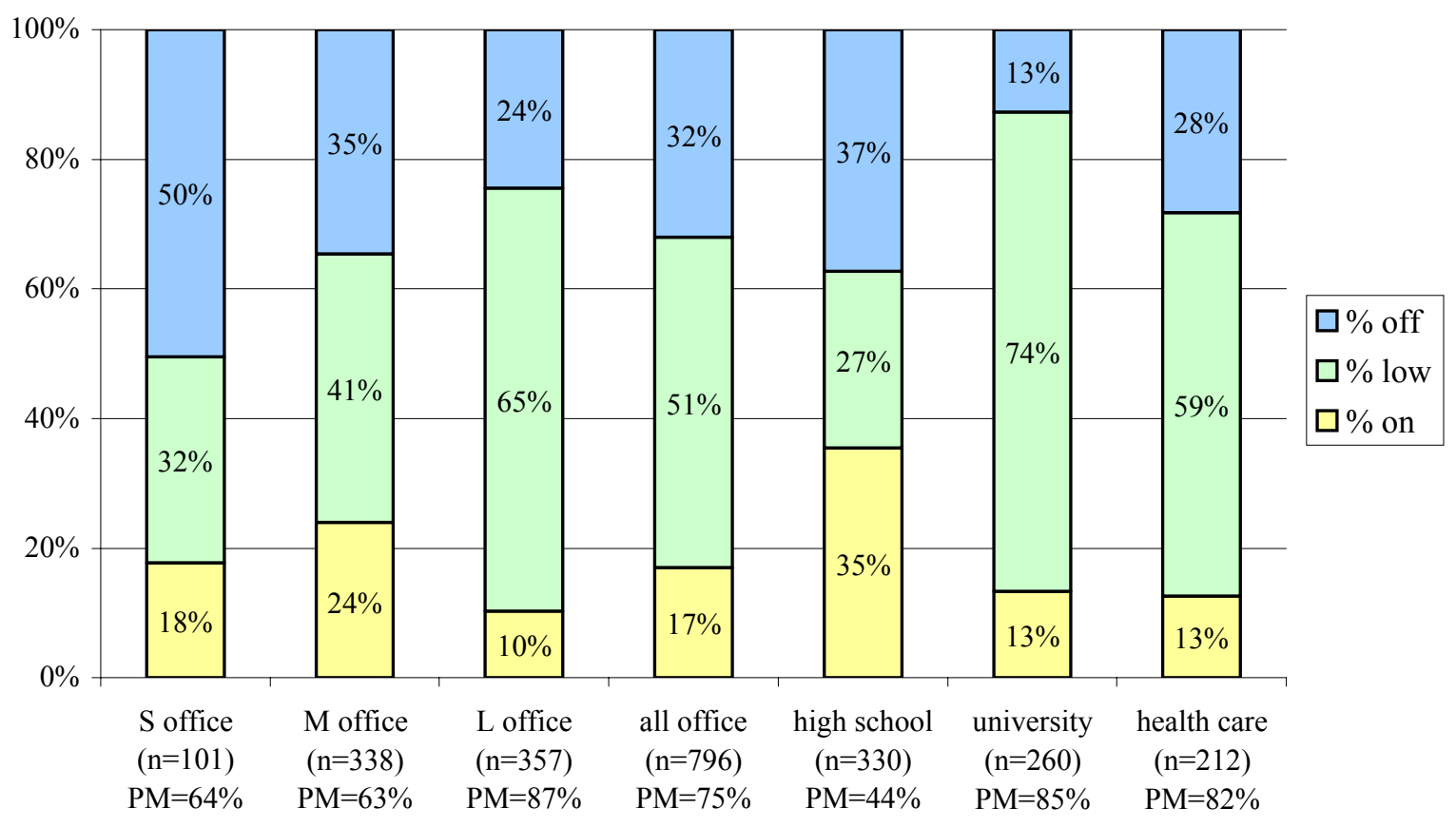




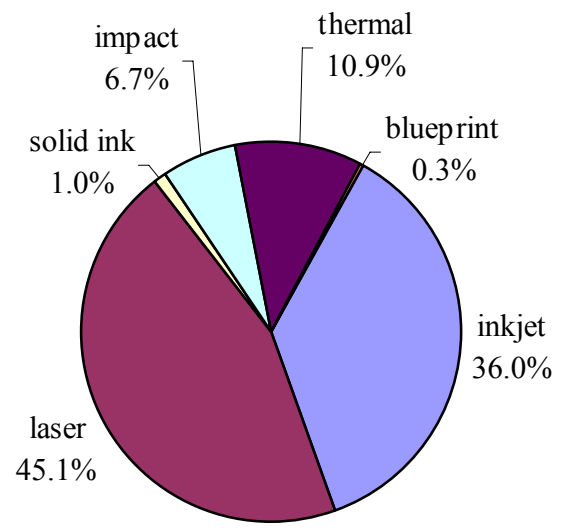

Figure 3. Printer sample, by technology 

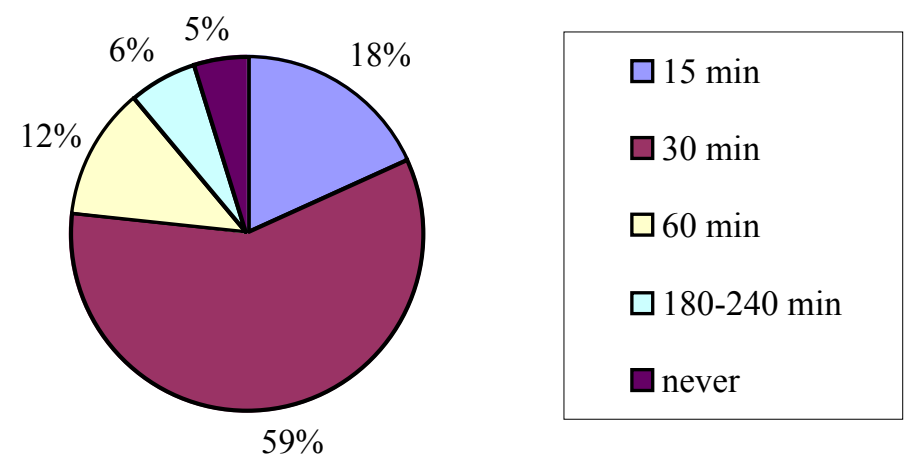

Figure 4. Laser printers: Power management delay settings 


